\title{
An XY/XYY Mosaic Cynomolgus Monkey (Macaca fascicularis)
}

\author{
Momoki Hirai ${ }^{1}$, Keiji Terao ${ }^{2}$, Fumiaki Cho ${ }^{2}$ and Shigeo Honjo ${ }^{2}$ \\ ${ }^{1}$ Department of Anthropology, Faculty of Science, University of \\ Tokyo, 7-3-1 Hongo, Bunkyo-ku, Tokyo 113, Japan \\ ${ }^{2}$ Tsukuba Primate Center for Medical Science, National Institute \\ of Health, Tsukuba, Japan
}

Accepted May 16, 1991

Chromosomal abnormalities have not often been reported in primate species other than man, possibly due to the relatively small number of individuals studied. The overall frequency of chromosome abnormalities in the human newborn population is estimated to be approximately $0.6 \%$ (Nielsen and Silessen 1975). Among such chromosome abnormalities in humans, an XYY seX-chromosome condition is comparatively common. The frequency of the XYY condition among the newborn male population is $0.1 \%$, with a further $0.02 \%$ showing mosaicism involving an XYY cell line (Nielen and Silessen 1975, Hook and Hamerton 1975, Jacobs 1979). The XYY condition has also been described in laboratory mice and rats (Cattanach and Pollard 1969, Rathenberg and Muller 1973, Evans et al. 1978, Das and Kar 1981, Yoshida 1984). A mosaic condition involving the $\mathrm{Y}$ chromosome has occasionally been observed in laboratory mice (Evans et al. 1969, Evans 1982, Das and Behera 1984), bulls (Dobryanov and Konstantinov 1970, Hanada and Muramatsu 1981, Miyake et al. 1984), the horse (Höhn et al. 1980) and a wild common shrew (Searle and Wilkinson 1986). Therefore, the frequency of identification of chromosome abnormalities in nonhuman primates can be expected to increase as more individuals are investigated.

To our knowledge, there have been no reports on the XYY condition in nonhuman primates. During a routine cytogenetic survey of the breeding colony of cynomolgus monkeys (Macaca fascicularis) at TPC (Tsukuba Primate Center for Medical Science, National Institute of Health) using blood specimens, we found an adult male that showed two distinct cell lines of diffcring chromosome constitution: 42, XY and 43, XYY. The present report summarizes cytogenetic findings of this case.

Materials and methods

\section{Animal}

The animal examined (ref. no. YY-11) was born in March, 1976 at the laboratory primate facility of NIH in Tokyo and moved to the breeding colony of TPC in 1978. The physical status at birth was normal, and the weight was $340 \mathrm{~g}$. The pedigree of the propositus is presented in Fig. 1. The parents had the same father (ref. no. 5825, a wild-originating male) but different mothers (half-brother-sister inbreeding). YY-11 grew well physically, showing normal behavioral and sexual maturation. However, this individual was euthanasized under anesthesia in December, 1984, because he had been severely emaciated exhibiting weight and total hair losses. At autopsy, no pronounced pathological changes were observed in any of the internal organs. The kidney tissue and the left testicle were removed for chromosome studies immediately after death.

\section{Somatic cells}

Peripheral blood lymphocytes were cultured in RPMI 1640 medium supplemented with 
$20 \%$ fetal calf serum (FCS) and 3\% phytohemagglutinin (PHA). After $46 \mathrm{hr}$ of culture, chromosome preparations were made. Approximately $1 \mathrm{~g}$ of the kidney tissue was minced with a pair of scissors and cultured in Eagle's minimum essential medium supplemented with $10 \%$ FCS. After 7 days of culture in a $\mathrm{CO}_{2}$ incubator, the proliferating cells were used for chromosome preparations.

\section{Germ cells}

Chromosome preparations were made according to the method of Meredith (1969) with slight modification. Spermatogonial cells, primary spermatocytes at stages between late diplotene and metaphase I (MI), and metaphase II (MII) spreads were scored with respect to sex-chromosome complement and pairing configurations.

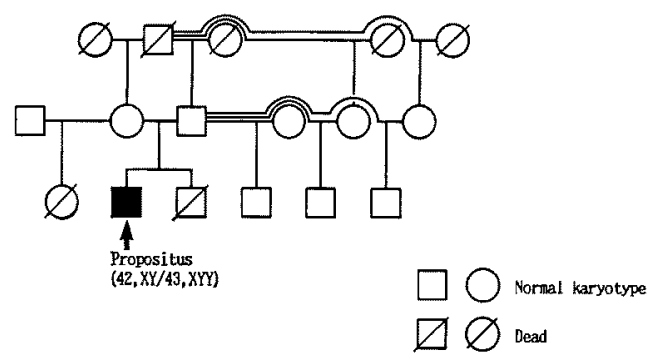

Fig. 1. Pedigree of the XY/XYY mosaic cynomolgus monkey (Macaca fascicularis).

Table 1. Distributions of chromosome counts in cultured lymphocytes, kidney cells and spermatogonia of the $\mathrm{XY} / \mathrm{XYY}$ mosaic cynomolgus monkey

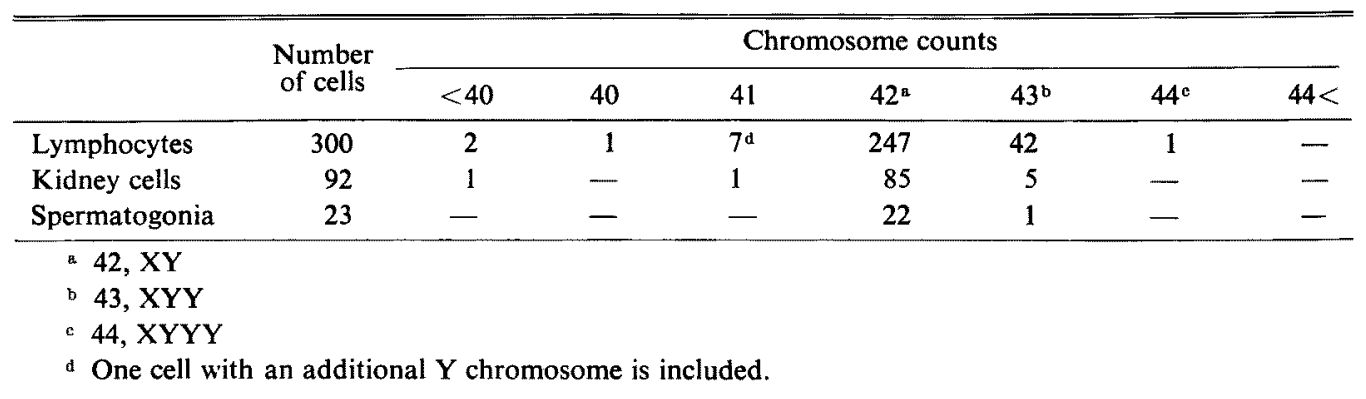

Results and discussion

Cytogenetic findings are summarized in Table 1. Of 300 lymphocyte metaphases analyzed, 42 cells $(14 \%)$ showed an extra chromosome having an identical size and shape to the $\mathrm{Y}$ chromosome (Fig. 2). The additional chromosome was confirmed to be the $\mathrm{Y}$ chromosome by both $\mathrm{C}$-banding and high resolution $\mathrm{G}$-banding analyses. No structural abnormalities were found in either the autosomes or the $X$ chromosome. One cell was found to possess two extra Y chromosomes (44, XYYY). Since the culture time was $46 \mathrm{hr}$, it is unlikely that the cells had passed two cell cycles after culture initiation. Thus, the cell with an XYYY sex-chromosome constitution was considered not to be the product of non-disjunction in vitro. It is, however, unclear whether there was another cell line with an XYYY condition in vivo.

Examination of the kidney chromosomes indicated that the frequency of cells with the 
$\mathrm{XYY}$ seX-chromosome condition $(5.4 \%)$ was significantly lower than in lymphocytes $\left(\chi^{2}=4.12\right.$, $P<0.05)$. In spermatogonial cells, however, the incidence of such XYY cells $(1 / 23)$ was not significantly different from those in lymphocytes $\left(\chi^{2}=0.99, P>0.25\right)$ and kidney cells $\left(\chi^{2}=\right.$ $0.10, P>0.75)$. It is not known whether these results indicate tissue differences in the rate of occurrence of XYY cells in vivo bacause the number of cells scored was small. Hypodiploid cells observed in both lymphocyte cultures and kidney cells were considered to be due to cell breakage during chromosome preparation. There was no evidence to suggest the presence of an XO cell line.

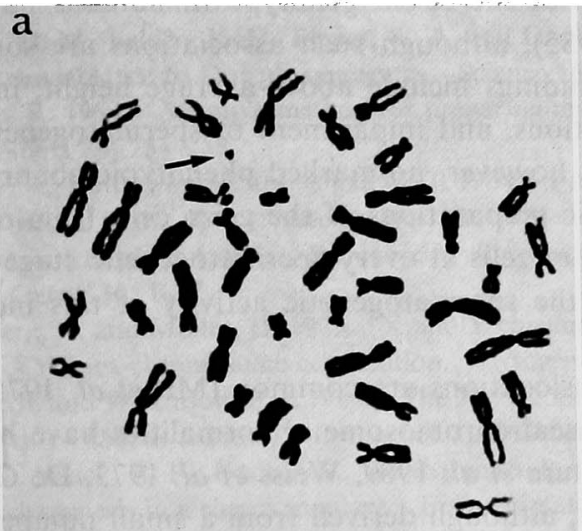

b

Fig. 2. Mitotic spreads of cultured lymphocytes from the XY/XYY mosaic cynomolgus monkey. (a) Normal karyotype showing one Y chromosome. (b) Abnormal karyotype showing two Y chromosomes. Arrows indicate $\mathrm{Y}$ chromosomes.

a

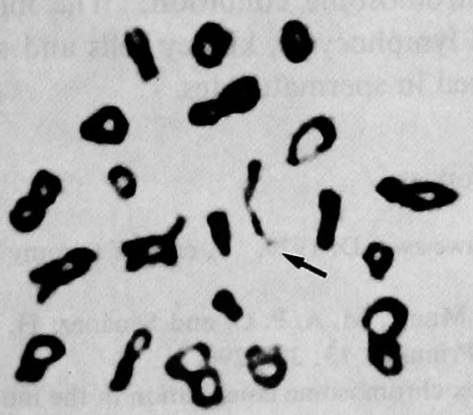

b

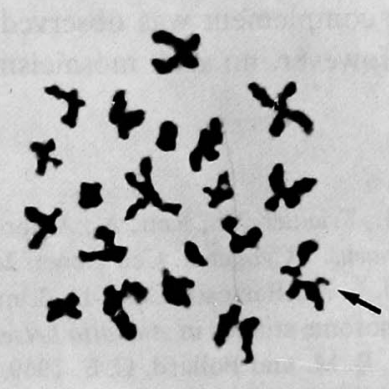

Fig. 3. (a) Normal primary spermatocyte spread showing an X-Y pairing configuration (arrow). (b) Normal meiotic MII spread $(n=21)$ showing a $Y$ chromosome (arrow).

Good numbers of late diplotene/diakinesis/MI and MII spreads were obtained (Fig. 3). Among the meiotic spreads analyzable (64 primary spermatocytes and $16 \mathrm{MII}$ ), however, the YY condition was not detected. Difficulties were encountered in scoring meiotic chromosomes because they often looked fuzzy. Moreover, the size of the Y chromosome was very small. This may sometimes have led to an underestimate of the number of $Y$ chromosomes. The 
discrepancy in the incidence of YY cells between spermatogonia and spermatocytes may be interpreted as being due to either the above-mentioned underestimation because of difficulties in scoring, or a mechanism resulting in selection against cells with the YY complement.

The presence of the XY and XYY cell lines in the three different systems suggests that the mosaicism arose by nondisjunction of the $\mathrm{Y}$ chromosome during an early mitotic division of an XY embryo with loss of the XO line. The results of pedigree studies indicated that no other members showed chromosomal abnormalities. The consanguinity of this pedigree did not seem to be associated with the occurrence of the mosaicism, although no evidence for this was available.

The physical characteristics associated with the XYY genotype in humans have been described in detail (for review, see Welch 1985), although such associations are sometimes controversial (Stewart 1982). The physical findings include above-average height, increased tooth size, psychological and hormonal deviations, and impairment of spermatogenesis. As for an XY/XYY mosaic condition in humans, however, no marked phenotypic abnormalities have been described so far. In the microscopic preparations of the germ cells from our XY/ XYY cynomolgus monkey, sufficient numbers of cells at every spermatogenetic stage including spermatozoa were observed. Therefore, the spermatogenetic activity of this individual was considered to be normal.

In platyrrhine monkeys, Y-autosome translocations are common (Ma et al. 1975, 1976, Armada et al. 1987). Several cases of numerical chromosome abnormalities have been described in catarrhine monkeys and apes (McClure et al. 1969, Weiss et al. 1973, De Grauchy et al. 1973, Andrle et al. 1979). These results, although derived from a small number of individuals, suggest that the number of cases of chromosome abnormality might increase as more population surveys are performed.

\section{Summary}

In the course of a cytogenetic population survey of the cynomolgus monkeys in the breeding colony of the Tsukuba Primate Center for Medical Science, we found a phenotypically normal male with an XY/XYY mosaic sex-chromosome condition. The mosaic sex-chromosome complement was observed in cultured lymphocytes, kidney cells and spermatogenial cells. However, no such mosaicism was detected in spermatocytes.

\section{References}

Andrle, M., Friedler, W., Rett, A., Ambros, P. and Schweizwe, D. 1979. A case of trisomy 22 in Pongo pygmaeus. Cyogenet. Cell Genet. 24: 1-6.

Armada, J. L. A., Barroso, C. M. L., Lima, M. M. C., Muniz, M. A. P. C. and Seuánez, H. N. 1987 . Chromosome studies in Alouatta belzebul. Am. J. Primatol. 13: 283-296.

Cattanach, B. M. and Pollard, C. E. 1969. An XYY sex chromosome constitution in the mouse. Cytogenet. Cell Genet. 8: 80-86.

Das, R. K. and Kar, R. N. 1981. A 41, XYY mouse. Experimentia 37: 821-822.

- and Behera, A. K. 1984. A 39, X/40, XY/41, XYY mosaic male mouse. Cytogenet. Cell Genet. 38: 138141.

De Grouchy, J., Turleau, C., Roubin, M. and Chavin-Colin, F. 1973. Chromosomal evolution of man and the primates (Pan troglodytes, Gorilla gorilla, Pongo pygmaeus). Nobel Symposium 23: 124-131.

Evans, E. P., Ford, C. E. and Searle, A. G. 1969. A 39, X/41, XYY mosaic mouse. Cytogenet. 8: 87-96.

-, Beechey, C. V. and Burtenshaw, M. D. 1978. Meiosis and fertility in XYY mice. Cytogenet. Cell Genet. 20: 249-263.

- 1982. A mosaic male mouse. Mouse News Letter 67: 29.

Hanada, H. and Muramatsu, S. 1981. A phenotypically normal cattle with 60, XY/61, XYY karyotype. Jpn. J. Genet. 56: 519-522. 
Hook, E. B. and Hamerton, J. L. 1977. The frequency of chromosome abnormalities detected in consequtive newborn studies - differences between studies-results by sex and by severity of phenotypic involvement. In Hook, E. B. and Porter, I. H. (eds.) Population Cytogenetics. Academic Press. pp. 63-79.

Hörn, H., Klug, E. and Rieck, G. W. 1980. A 63, XO/65, XYY mosaic in a case of questionable equine male pseudohermaphroditism. In Fourth European Colloquium on the Cytogenetics of Domestic Animals. pp. 82-92.

Jacobs, P. A. 1979. The incidence and etiology of sex chromosome abnormalities in man. Birth Defects 15: $3-14$.

Ma, N. S. F., Jones, T. C., Thorington, R. W., Miller, A. and Morgan, L. 1975. Y-autosome translocation in the howler monkey, Alouatta pallieta. J. Med. Primatol. 4: 299-307.

-, Elliott, M. W., Morgan, L., Miller, A. and Jones, T. C. 1976. Translocation of Y chromosome to an autosome in the Bolivian owl monkey, Aotus. Am. J. Phys. Anthop. 45: 191-201.

McClure, H. M., Belden, K. H., Pieper, W. A. and Jacobson, C. B. 1969. Autosomal trisomy in a chimpanzee; resemblance to Down's syndrome. Science 165: 1010-1012.

Meredith, R. 1969. A simple method for preparing meiotic chromosomes from mammalian testis. Chromosoma 26: 254-258.

Miyake, Y-I., Kanagawa, H. and Ishikawa, T. 1984. Further chromosomal and clinical studies on the XY/XYY mosaic bull. Jpn. J. Veterin. Res. 32: 9-21.

Nielsen, J. and Silessen, I. 1975. Incidence of chromosome aberration among 11, 148 newborn children. Hum. Genet. 30: 1-12.

Rathenberg, R. and Müller, D. 1973. X and $Y$ chromosome pairing and disjunction in a male mouse with an XYY sex-chromosome constitution. Cytogenet. Cell Gene. 12: 87-91.

Searle, J. B. and Wilkinson, P. J. 1986. The XYY condition in a wild mammal: an XY/XYY mosaic common shrew (Sorex araneus). Cytogenet. Cell Genet. 41: 225-233.

Weiss, G., Weick, R. F., Knobil, E., Wolmanm, S. R. and Gorstein, F. 1973. An X-O anomaly and ovarian dysgenesis in a rhesus monkey. Folia Primatol. 19: 24-27.

Welch, J. P. 1985. Clicical aspects of the XYY syndrome. In Sandberg, A. A. (ed.) The Y Chromosome. Alan R. Liss, Inc., New York. pp. 323-343.

Yoshida, T. H. 1984. Studies on the karyotype differentiation of the Norway rat. IX. Translocation between pair nos. 4 and 7 occurred in a segregation in a WM strain rat after 7 -irradiation, with special regard to the segregation in $F_{1}$ hybrids involving an XYY male. Proc. Jpn. Acad. 60: 88-91. 